\title{
An Analytical Formula for Potential Water Vapor in an Atmosphere of Constant Lapse Rate
}

\author{
Ali Varmaghani * \\ IIHR-Hydroscience \& Engineering, University of Iowa, Iowa, USA
}

Received 1 July 2010, accepted 28 June 2011

\begin{abstract}
Accurate calculation of precipitable water vapor (PWV) in the atmosphere has always been a matter of importance for meteorologists. Potential water vapor (POWV) or maximum precipitable water vapor can be an appropriate base for estimation of probable maximum precipitation (PMP) in an area, leading to probable maximum flood (PMF) and flash flood management systems. PWV and POWV have miscellaneously been estimated by means of either discrete solutions such as tables, diagrams or empirical methods; however, there is no analytical formula for POWV even in a particular atmospherical condition. In this article, fundamental governing equations required for analytical calculation of POWV are first introduced. Then, it will be shown that this POWV calculation relies on a Riemann integral solution over a range of altitude whose integrand is merely a function of altitude. The solution of the integral gives rise to a series function which is bypassed by approximation of saturation vapor pressure in the range of -55 to 55 degrees Celsius, and an analytical formula for POWV in an atmosphere of constant lapse rate is proposed. In order to evaluate the accuracy of the suggested equation, exact calculations of saturated adiabatic lapse rate (SALR) at different surface temperatures were performed. The formula was compared with both the diagrams from the US Weather Bureau and SALR. The results demonstrated unquestionable capability of analytical solutions and also equivalent functions.
\end{abstract}

Key words: Precipitable water vapor, Lapse rate, Troposphere, Meteorology

Citation: Varmaghani, A., 2012: An analytical formula for potential water vapor in an atmosphere of constant lapse rate. Terr. Atmos. Ocean. Sci., 23, 1724, doi: 10.3319/TAO.2011.06.28.01(A)

\section{INTRODUCTION}

The distribution of water vapor in the atmosphere has always been noticed in different aspects. It plays a key role in the balance of planetary radiation; it affects and reacts to atmospheric motions; and it is a key component in many features of atmospheric processes acting over a wide range of spatial and temporal scales (Jade et al. 2005). It is particularly material, in terms of the potential impact on climate change and to assess long-term changes and decadal scale trends of the atmospheric water vapor regime (Jacob 2001). "Precipitable water vapor (PWV) is a measure of the total water contained in a vertical column above the site. It is commonly expressed as the resulting height of liquid water if the entire vapor in the column were condensed" (Marvil et al. 2006). Some studies have demonstrated that PWV es-

\footnotetext{
* Corresponding author

E-mail:ali-varmaghani@uiowa.edu
}

timates from ground-based global positioning system (GPS) observations and meteorological data yield the same level of accuracy as radiosondes and microwave radiometers (Jade et al. 2005; Jade and Vijayan 2008). Many authors implemented research to increase the precision of the technique for GPS-based PWV estimation, typically exploiting a small number of stations. Rocken et al. (1995) were the first to show the concord between water vapor radiometer (WVR) and GPS derived relative estimates of integrated water vapor (IWV), with a level of agreement of about $1 \mathrm{~kg} \mathrm{~m}^{-2}$.

Svensson and Rakhecha (1998) assumed in their hydrometeorological method for determination of probable maximum precipitation (PMP) that PMP will result from a storm where there is an optimum integration of available moisture in the atmosphere and efficiency of the storm mechanism. Factors that influence storm efficiency comprise horizontal mass convergence, vertical velocity by frontal or 
topographically induced lifting, and the rate of condensation of water vapor into droplets. At present, it is impossible to assess the above-mentioned factors separately, and therefore the observed highest rainfall is employed as an indirect measure of storm efficiency. After the Banqiao and Shimantan dams in China were built in the 1950s, estimation methods of the inflow design flood for dam safety have greatly altered with improvements in hydrometeorological techniques. These new techniques exploit meteorological theories and concepts to determine a design storm of a probable maximum precipitation (PMP) magnitude (Svensson and Rakhecha 1998). The PMP is then transformed into a probable maximum flood (PMF) hydrograph after deduction of losses and determination of antecedent properties, such as soil moisture content (Pilgrim and Cordery 1993). The application of PMP to estimate the PMF has become a standard for dam design in some countries where no risk of overtopping can be approved: e.g., the USA (e.g., Riedel 1976; USNWS 1978; Hansen 1987), Canada (e.g., Gagnon et al. 1970), China (e.g., Wang 1987; Pan and Teng 1988), India (e.g., CWC 1972; Rakhecha et al. 1990), and Australia (e.g., Kennedy 1982). Hence, the importance of maximum precipitable water vapor or potential water vapor (POWV) in an area is revealed.

Wang et al. (2009) demonstrated that a GPS survey is an effective way of monitoring the PWV alteration. It can continuously render both the temporal and spatial distribution of atmospheric water vapor. They utilized the time series data of GPS zenith tropospheric delays (ZTD), derived continuously from 28 permanent GPS sites from 2002 to 2004 , to analyze the change of precipitable water vapor on the Chinese mainland. Valeo et al. (2005) performed studies on PWV estimation - derived from GPS zenith wet delay measurements - in conjunction with a basic snow evaporation model to verify observations of snow evaporation in an open urban area. Kumar et al. (2005) developed a simple theoretical model for computing global insolation on a horizontal surface. The input parameters for the model were the latitude of the desired location and the amount of total precipitable water content in the vertical column at that location. Jade et al. (2005) estimated the precipitable water vapor from GPS data over the Indian subcontinent for a 3-year period (2001 - 2003).

The total amount of water vapor in a layer of air is often expressed as the depth of precipitable water $l_{P W V}$ even though there is no natural process capable of precipitating the entire moisture content of the layer (Linsley et al. 1975). Marvil et al. (2006) calculated PWV by means of two methods; in the first method, they represented the depth of PWV as a fraction of sea-level water vapor density. An atmospheric modeling program (ATMOS) was utilized to compute the mentioned depth, $l_{P W V}$, at $3.8 \mathrm{~km}$ for a range of sea-level water vapor density $\rho_{0}$. They worked out a linear fit between PWV and $\rho_{0}$ through the following equation:
$l_{P W V}=0.174 \rho_{0}$

where $l_{P W V}$ is the depth of precipitable water vapor in $\mathrm{mm}$, and $\rho_{0}$ is sea-level water vapor density in $\mathrm{gr} \mathrm{m}^{-3}$. In the second method, the Magnus-Teten equation was used to determine the depth of PWV. The Magnus-Teten equation is assessed at the dew point to estimate the local vapor pressure of water. This is given by Eq. (2):

$\log _{10} P_{v p}=\frac{7.5 T_{d}}{T_{d}+237.3}+0.7858$

where $P_{v p}$ is the vapor pressure of $\mathrm{H}_{2} \mathrm{O}$ in $\mathrm{hPa}$ and $T_{d}$ is the dew point temperature in degrees Celsius (Murray 1967). This is applied to estimate integrated $l_{P W V}$ from an atmospheric model as shown in Eq. (3):

$l_{P W V}=2.1 P_{v p}(h) 10^{-h / 22}$

where $h$ is the height in kilometers and $P_{v p}(h)$ is the vapor pressure of $\mathrm{H}_{2} \mathrm{O}$ in $\mathrm{mmHg}$ at height $h$ (Allen 1973). Solot (1939) proposed the following discrete formula to calculate the amount of precipitable water in any air column of considerable height:

$l_{P W V}=\sum 0.0004 q_{h} \Delta p_{a}$

in which $l_{P W V}$ is precipitable water in inches; $p_{a}$ is the air pressure in millibars; and $q_{h}$ is the average of the specific humidity at the top and bottom of each layer in grams per kilogram. Following the Solot equation, the US Weather Bureau (USWB 1949) published charts of mean precipitable water in the atmosphere over the United States. Figure 1 presents the depth of precipitable water in a column of saturated air with its base at the 1000-millibar level and its top anywhere up to 200 millibars, assuming saturation and pseudo-adiabatic lapse rate. USWB (1949) also has provided tables for computing precipitable water in the atmosphere over the United States.

\section{METHODOLOGY}

Knowledge of the vertical and spatial distribution of moisture allows the calculation of the precipitable water in an area. In order to compute the total amount of precipitable water $l_{P W V}$ in a layer between elevations 0 and $z$, it is required to evaluate the following integral:

$l_{P W V}=\int_{0}^{z} \rho_{v} d z$

where $\rho_{v}$ is the water content (vapor density) in the column 
(Bras 1990). Specific humidity, $q_{h}$, is the mass of water, $\rho_{v}$, per unit mass of moist air, $\rho_{m}$, and can be determined by Eq. (6):

$q_{h}=\frac{\rho_{v}}{\rho_{m}}=\frac{0.622 e}{p-0.378 e} \approx \frac{0.622 e}{P}$ where $e$ and $P$ are vapor pressure and total atmospheric pressure in millibars, respectively (Bras 1990). The amalgamation of Eqs. (5) and (6) yields:

$l_{P W V}=0.622 \int_{0}^{z} \frac{\rho_{m}}{P} e d z$
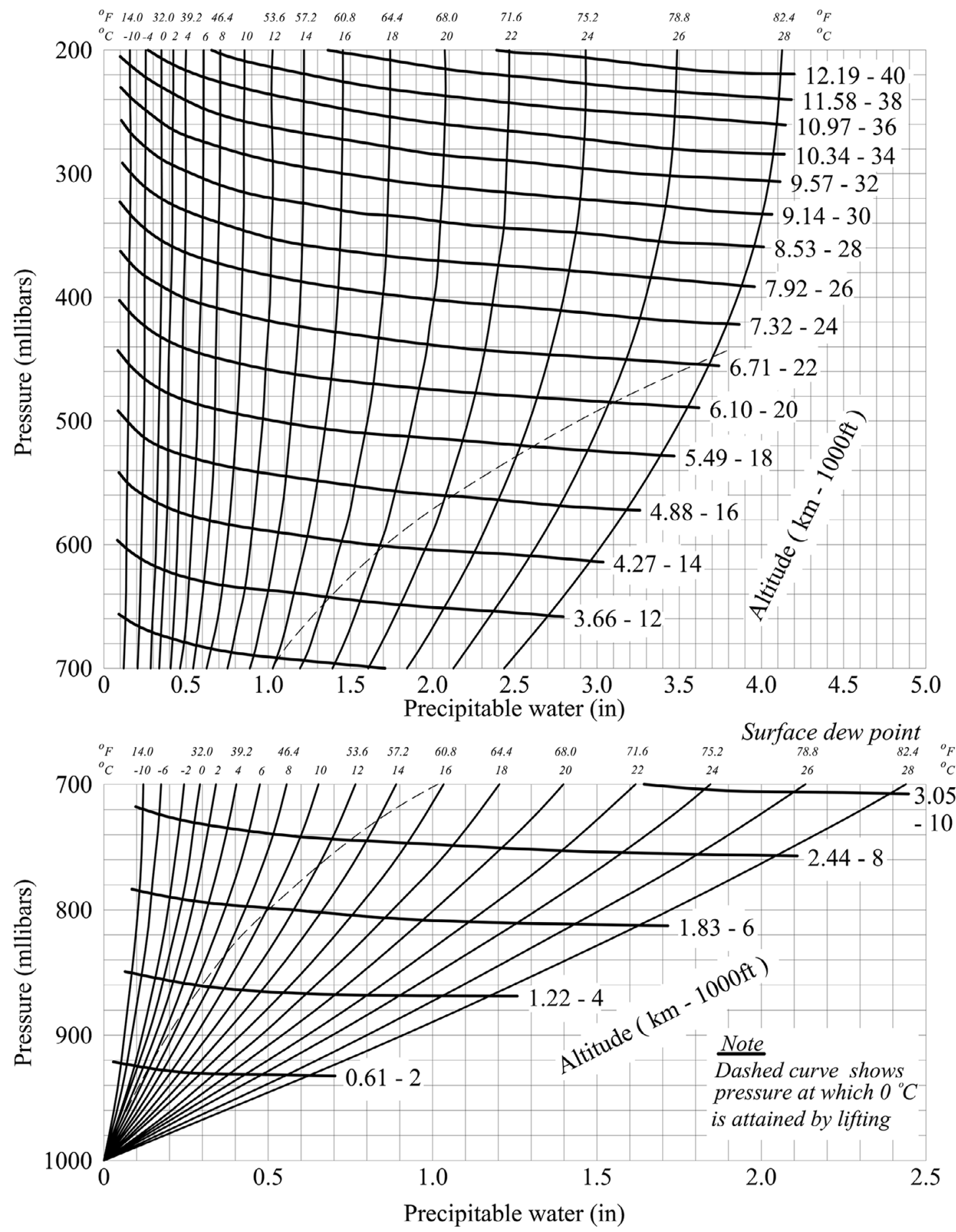

Fig. 1. Depths of precipitable water in a column of air of any height above 1000 millibars as a function of dew point, assuming saturation and pseudo-adiabatic lapse rate (USWB 1949). 
Saturation vapor pressure for water in millibars can be estimated by:

$e_{s}=6.1078 \exp \left[\frac{17.2693882\left(T^{\prime}-273.16\right)}{T^{\prime}-35.86}\right]$

where $T^{\prime}$ is the air temperature in degrees Kelvin (Potter and Colman 2003). Therefore, saturation vapor pressure in Pascal can be shown as follows:

$e_{s}=610.78 \exp \left(\frac{17.2693882 T}{T+237.29}\right)$

where $T$ is the air temperature in degrees Celsius. The parameters $e$ and $e_{s}$ are related to each other through the following equation:

$e=\frac{r}{100} e_{s}$

in which $r$ is relative humidity or the ratio of the vapor density (or pressure) to the saturation vapor density (saturation vapor pressure) at the same temperature (Bras 1990).

Air in the atmosphere follows, reasonably well, the ideal gas law, which for a unit mass is:

$\frac{\rho_{m}}{P}=\frac{1}{R T^{\prime}}$

where $R$ is gas constant in square centimeters per square second per degree Kelvin, and $T^{\prime}$ is ambient air temperature in degrees Kelvin (Bras 1990). The relation between degrees Kelvin $\left(T^{\prime}\right)$ and degrees Celsius $(T)$ is:

$T^{\prime}=T+273.15$

The troposphere, the lowest layer of the air, is characterized by a nearly uniform decrease in temperature. Most of the weather changes in the air are limited to this layer. Its average thickness reaches about $11.3 \mathrm{~km}$ (Donn 1965). The temperature variation in the troposphere is assumed to be linear (or piecewise linear):

$T=T_{0}-\alpha z$

where $T$ and $T_{0}$ are ambient temperature at elevation $z$ and surface temperature, sequentially. The rate of cooling $\alpha$ is called the ambient lapse rate and usually varies between 5 and $8^{\circ} \mathrm{C} \mathrm{km}^{-1}$ (Bras 1990). The depth of potential water vapor, $l_{P O W V}$, is obtainable when the entire layer becomes saturated $(r=100)$. Inserting Eqs. (9) through (13) in Eq. (7), assuming $r=100$ results in the following equation:

$l_{\text {POWV }}=\frac{0.622 \times 610.78}{R} \int_{0}^{z} \frac{\exp \left[\frac{17.2693882\left(T_{0}-\alpha z\right)}{237.29+\left(T_{0}-\alpha z\right)}\right]}{\left(T_{0}-\alpha z\right)+273.15} d z$

The integrand in Eq. (14) is merely a function of altitude. Having solved the Riemann integral in the above-mentioned equation by means of three variable substitutions, the potential water vapor in an atmosphere of constant lapse rate is obtained by:

$l_{\text {POWV }}=\frac{k}{\alpha R}\left[e^{a}\left(\ln \frac{A}{A_{0}}+\sum_{n=1}^{\infty} \frac{A^{n}-A_{0}^{n}}{n^{*} n !}\right)-e^{b}\left(\ln \frac{B}{B_{0}}+\sum_{n=1}^{\infty} \frac{B^{n}-B_{0}^{n}}{n^{*} n !}\right)\right]$

where $l_{P O W V}$ is the depth of potential water vapor in a column of air with height $z$ in terms of mm. $a, b$ and $k$ are the equation constants; $A, A_{0}, B$ and $B_{0}$ are the equation parameters, presented in Table 1, which are functions of $T, T_{0}$ and $\alpha . T$ and $T_{0}$ should be in degrees Celsius, and $\alpha$ is in terms of ${ }^{\circ} \mathrm{C} \mathrm{km}^{-1}$. A simpler integral form of $l_{P O W V}$ is:

$l_{\text {POWV }}=\frac{k(a-b)}{\alpha R} \int_{l_{0}}^{l} \frac{e^{x}}{(x-a)(x-b)} d x$

$l_{0}=\frac{a T_{0}}{T_{0}+237.29}$

$l=\frac{a\left(T_{0}-\alpha z\right)}{\left(T_{0}-\alpha z\right)+237.29}$

Saturation vapor pressure over water can be approximated within $1 \%$ in the range of -50 to $55^{\circ} \mathrm{C}$ by:

$$
\begin{aligned}
e_{s} \approx & 33.8639\left[(0.00738 T+0.8072)^{8}\right. \\
& -0.000019|1.8 T+48|+0.001316]
\end{aligned}
$$

Table 1. The value of the parameters in Eq. (15).

\begin{tabular}{cl}
\hline Parameter & Value \\
\hline$a$ & 17.2693882 \\
$b$ & 131.5430392 \\
$k$ & 379.90516 \\
$A$ & $(-237.29 a) /\left(T_{0}-\alpha z+237.29\right)$ \\
$A_{0}$ & $(-237.29 a) /\left(T_{0}+237.29\right)$ \\
$B$ & {$\left[(a-b)\left(T_{0}-\alpha z\right)-237.29 b\right] /\left(T_{0}-\alpha z+237.29\right)$} \\
$B_{0}$ & {$\left[(a-b) T_{0}-237.29 b\right] /\left(T_{0}+237.29\right)$} \\
\hline
\end{tabular}


where $e_{s}$ is in millibars and $T$ is ambient temperature in degrees Celsius (Bosen 1960). Comparing Eq. (9) with Eq. (19) implies the maximum error of $4.6 \%$ occurring at $-50^{\circ} \mathrm{C}$. The diagram published by the US Navy Weather Research Facility, illustrating the physical structure of the atmosphere, shows the minimum possible temperature in the troposphere around $-55^{\circ} \mathrm{C}$ (Donn 1965). Therefore, in order to find an indefinite integral for Eq. (14), another approximation of Eq. (9) was made in the range of -55 to $55^{\circ} \mathrm{C}$ within maximum and mean error of 4.5 and $0.5 \%$, respectively:

$$
\begin{aligned}
e_{s} \approx & 6.423 * 10^{-9} T^{6}+2.047 * 10^{-6} T^{5}+0.0003015 T^{4} \\
& +0.02642 T^{3}+1.43 T^{2}+44.44 T+610.78
\end{aligned}
$$

where $e_{s}$ is in Pascal and $T$ is ambient temperature in degrees Celsius. Having inserted Eq. (20) in Eq. (14), instead of Eq. (9), and solving the integral, potential water vapor in $\mathrm{mm}$ is readily obtained by the following formula:

$$
\begin{aligned}
l_{\text {POWV }}= & \frac{-1}{R \alpha}\left[A\left(T_{z}^{6}-T_{0}^{6}\right)+B\left(T_{z}^{5}-T_{0}^{5}\right)+C\left(T_{z}^{4}-T_{0}^{4}\right)+D\left(T_{z}^{3}-T_{0}^{3}\right)\right. \\
& \left.+E\left(T_{z}^{2}-T_{0}^{2}\right)+F\left(T_{z}-T_{0}\right)+G \ln \left(\frac{T_{z}+273.15}{T_{0}+273.15}\right)\right]
\end{aligned}
$$

where $A, B, C, D, E, F$ and $G$ are the equation constants, presented in Table 2. $T_{z}$ is the ambient temperature at height $z$ in degrees Celsius. The other parameters in Eq. (21) are as defined earlier. Eqs. (16) and (21) are applicable as long as temperature variation in the desired limit is linear (i.e., the assumption of constant lapse rate).

\section{DISCUSSION AND CONCLUSION}

In this study, it was revealed that analytical computation of POWV relies on a Riemann integral solution over a range of altitude whose integrand is merely a function of altitude. The solution yielded a series function which was circumvented by approximation of saturation vapor pressure in the range of -55 to 55 degrees Celsius, and a formula for POWV in an atmosphere of constant lapse rate was successively proposed.

The formula [i.e., Eq. (21)] was verified and compared with the diagrams (Fig. 1) published by USWB (1949). A comparison was optionally carried out at different heights for the temperatures 10,20 and $28^{\circ} \mathrm{C}$. The gas constant, $R$, was taken $287 \mathrm{~cm}^{2} \mathrm{sec}^{-2}{ }^{\circ} \mathrm{K}^{-1}$. Table 3 compares $l_{\text {POWV }}$ obtained from Eq. (21) with USWB diagrams. It is necessary to state that USWB assumptions for lapse rate value $(\alpha)$ are not explicitly mentioned since their calculations were on the basis of pseudo-adiabatic lapse rate. Comparing Eq. (21) with Eq. (16) at normal meteorological conditions implies maximum and mean error of 0.066 and $0.008 \%$, respectively. For instance, an error of $0.063 \%$ is observable between the two formulae at sea level temperature $10^{\circ} \mathrm{C}$ with ambient lapse rate $6^{\circ} \mathrm{C} \mathrm{km}^{-1}$ in a $10 \mathrm{~km}$ saturated layer $\left[l_{\text {POWV }}\right.$ is obtained $21.873 \mathrm{~mm}$ from Eq. (16)].

An atmosphere of constant lapse rate only occurs when the atmosphere is moisture free. When the air is fully saturated the atmosphere becomes unstable, and in an adiabatic process, vertical temperature gradient of standard atmosphere follows saturation adiabatic lapse rate (SALR):

$$
\alpha_{s}=\frac{g}{c_{p}+L \frac{d}{d T}\left(w_{s}\right)}
$$

where $\alpha_{s}$ is SALR in ${ }^{\circ} \mathrm{C} \mathrm{km}^{-1} ; g$ is acceleration due to gravity $\left(\mathrm{m} \mathrm{s}^{-2}\right) ; c_{p}$ denotes heat capacity of dry air at constant pressure in $\mathrm{J} \mathrm{kg}^{-1} ; L$ represents latent heat of condensation in $\mathrm{J} \mathrm{kg}^{-1}$, and $w_{s}$ is mixing ratio of the mass of water vapor to the mass of dry air (Wallace and Hobbs 1977). The second term in the denominator of Eq. (22) indicates the presence of water vapor. In order to compare POWV obtainable from constant lapse rate and POWV from SALR, Exact calculation for SALR was performed in the sense that acceleration due to gravity, $g$, was obtained through the following formula:

$g=G \frac{M_{e}}{\left(R_{e}+z\right)^{2}}$

where $G$ is gravitational constant, equal to $6.673 * 10^{-11}$ $\mathrm{N} \mathrm{m}^{-2} \mathrm{~kg}^{2} ; M_{e}$ is the earth's mass $\left(5.98 * 10^{24} \mathrm{~kg}\right) ; R_{e}$ is the earth's radius which is approximately $\left(6.38 * 10^{6} \mathrm{~m}\right)$; and $z$ is the altitude in $\mathrm{m}$ (Bourg 2002). Heat capacity of dry air at constant pressure, $c_{p}$, in $\mathrm{J} \mathrm{kg}^{-1}$ was precisely determined by:

$c_{p}=R\left(\alpha+\beta T+\gamma T^{2}+\delta T^{3}+\varepsilon T^{4}\right)$

where $T$ is in Kelvin, and $\alpha, \beta, \gamma, \delta$, and $\varepsilon$ are constant and have the values of $3.653,-1.337 * 10^{-3}, 3.294 * 10^{-6},-1.913 *$ $10^{-9}$ and $0.2763 * 10^{-12}$ for air respectively (Moran et al. 2011). Latent heat of condensation of water vapor $(L)$ was approximated by:

Table 2. The value of the constants in Eq. (21).

\begin{tabular}{cl}
\hline Constant & Value \\
\hline$A$ & $6.65851 \mathrm{E}-10$ \\
$B$ & $3.639415922 \mathrm{E}-08$ \\
$C$ & $3.44569192613 \mathrm{E}-05$ \\
$D$ & $-7.0714633 \mathrm{E}-03$ \\
$E$ & 3.342085312 \\
$F$ & -1798.139526 \\
$G$ & 491541.7167 \\
\hline
\end{tabular}


Ali Varmaghani

Table 3. A comparison between Eq. (21) and USWB diagrams for $l_{P O W V}$.

\begin{tabular}{|c|c|c|c|c|c|c|c|c|c|}
\hline \multirow[t]{2}{*}{$\begin{array}{c}\text { Height } \\
\text { (km) }\end{array}$} & $T_{0}=10^{\circ} \mathrm{C}$ & $6^{\circ} \mathrm{C} \mathrm{km}^{-1}$ & $\begin{array}{c}\text { Error } \\
(\%)\end{array}$ & $T_{0}=20^{\circ} \mathrm{C}$ & $.9^{\circ} \mathrm{C} \mathrm{km}^{-1}$ & $\begin{array}{c}\text { Error } \\
(\%)\end{array}$ & $T_{0}=28^{\circ} \mathrm{C}$ & $4^{\circ} \mathrm{C} \mathrm{km}^{-1}$ & \multirow[t]{2}{*}{$\begin{array}{c}\text { Error } \\
(\%)\end{array}$} \\
\hline & diagram & Eq. (21) & & diagram & Eq. (21) & & diagram & Eq. (21) & \\
\hline 10.34 & 0.86 & 0.862 & 0.2 & 2.07 & 2.069 & 0.0 & 4.06 & 4.095 & 0.9 \\
\hline 8.53 & 0.85 & 0.855 & 0.6 & 2.06 & 2.024 & 1.8 & 3.95 & 3.922 & 0.7 \\
\hline 7.32 & 0.85 & 0.845 & 0.6 & 2.02 & 1.967 & 2.7 & 3.80 & 3.744 & 1.5 \\
\hline 6.1 & 0.84 & 0.823 & 2.1 & 1.94 & 1.876 & 3.4 & 3.55 & 3.490 & 1.7 \\
\hline 4.88 & 0.80 & 0.783 & 2.2 & 1.79 & 1.732 & 3.3 & 3.18 & 3.140 & 1.3 \\
\hline 3.66 & 0.73 & 0.709 & 3.0 & 1.57 & 1.513 & 3.8 & 2.72 & 2.659 & 2.3 \\
\hline 2.44 & 0.60 & 0.579 & 3.6 & 1.22 & 1.183 & 3.1 & 2.05 & 2.011 & 1.9 \\
\hline 1.22 & 0.37 & 0.360 & 2.8 & 0.71 & 0.699 & 1.6 & 1.17 & 1.144 & 2.3 \\
\hline
\end{tabular}

$$
\begin{aligned}
L= & -0.0000614342 T^{3}+0.00158927 T^{2}-2.36418 T \\
& +2500.79
\end{aligned}
$$

where $T$ is in degrees Celsius (Rogers 1976). $w_{s}$ in Eq. (22) is defined by:

$w_{s}=0.622 \frac{e_{s}}{p-e_{s}}$

where $p$ is total pressure. Total pressure at elevation $z, p$, is dependant of lapse rate and was obtained up to $11 \mathrm{~km}$ from International Standard Atmosphere (ISA) model:

$p=p_{0}\left(1-\frac{\alpha z}{T_{0}}\right)^{\frac{g}{R_{d} \alpha}}$

where $R_{d}$ is dry air gas constant (Iribarne and Godson 1986).

The mentioned equations indicate that saturation adiabatic lapse rate is a function of temperature and pressure while temperature and pressure are functions of SALR too. Therefore, a trial-and-error layer-by-layer algorithm was performed in MATLAB to compute SALR. The equations also imply that precise calculation of SALR is feasible only if the troposphere is divided into several sub-layers provided that the premise of constant lapse rate for each layer maintains the accuracy of computations. The height of each layer was conservatively assumed $10 \mathrm{~m}$ - yielding less than $1 \%$ error for the value of SALR if the entire troposphere shows the variation of at most $10^{\circ} \mathrm{C} \mathrm{km}^{-1}$. Therefore, the troposphere was divided into 1100 layers. It should be noted that Eq. (27) was considered to be piecewise valid for saturated air: for each layer, its own value of SALR was used in Eq. (27).
Figure 2 aptly reflects the diagrams of SALR vs. altitude for three surface temperatures. As can be seen, temperature gradient or SALR in the troposphere increases with altitude and generally has the lower values at higher surface temperatures $\left(T_{0}\right)$. As observable in Fig. 2, the range of SALR lies between 3.6 to $9.8^{\circ} \mathrm{C} \mathrm{km}^{-1}$ for normal surface temperatures. POWV obtained from the assumption of constant lapse rate was compared with POWV from SALR at $15^{\circ} \mathrm{C}$ surface temperature. Average value for constant lapse rate was chosen in the sense that both POWVs become equal at the tropopause (see Fig. 3). Those two POWV curves in Fig. 3 were generated by Eq. (21). The result demonstrated that the assumption of constant lapse rate produces maximum error of $5.36 \%$ at altitude of $4.44 \mathrm{~km}$ in comparison with values of lapse rate due to SALR at $15^{\circ} \mathrm{C}$ surface temperature. The average error was proved to be $3.24 \%$ at the mentioned atmospheric condition.

The obtained result in this study may offer that POWV estimation based on constant lapse rate does not lead to unsatisfactory errors, and hence encourages analytical solutions. The superiority of the proposed analytical formulae over USWB tables and diagrams, as well as their high accuracy, is that mathematical relations are not limited while tables and diagrams just cover some specific values. USWB diagrams also present POWV merely above the sea level (where the base altitude is zero) while the suggested equations are suitable not only above the ocean but also above mountainous zones and hence they are more appropriate for grid-based models. The results achieved in this study demonstrated flexibility and high capability of analytical solutions beside discrete and empirical methods. For future studies, it is suggested that new contributions are made to estimate latent heat of vaporization for broader ranges since Eq. (25) estimates $L$ within the range of -40 to $40^{\circ} \mathrm{C}$ which does not cover the variation of atmosphere temperature. 


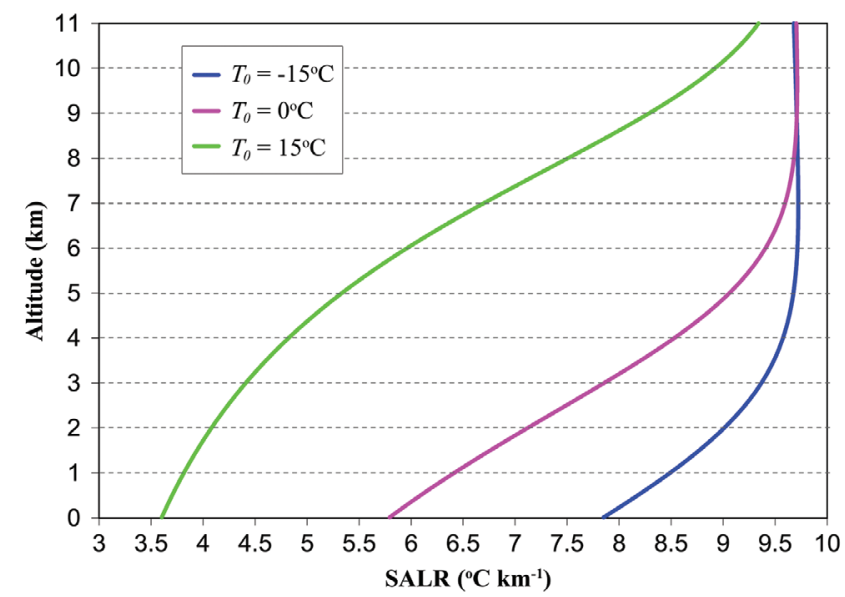

Fig. 2. Values of saturated adiabatic lapse rate (SALR) in ${ }^{\circ} \mathrm{C} \mathrm{km}^{-1}$ at different surface temperatures $\left(T_{0}\right)$ for standard atmosphere.

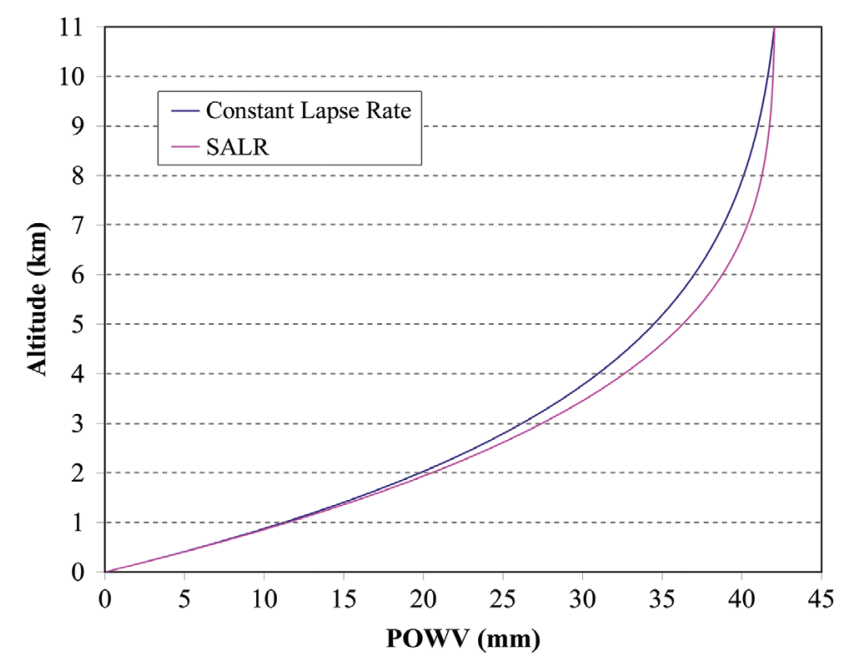

Fig. 3. Comparison between POWV obtained from constant lapse rate and SALR at surface temperature of $15^{\circ} \mathrm{C}$.

Acknowledgements The author would like to thank the anonymous journal reviewers for their constructive remarks. This work was accomplished under partial support of Iowa Flood Center. I also appreciate professors William Eichinger and Allen Bradley for their guidance.

\section{REFERENCES}

Allen, C. W., 1973: Astrophysical Quantities, $3^{\text {rd }}$ Ed., the Athlone Press, London, $120 \mathrm{pp}$.

Bosen, J. F., 1960: A formula for approximation of the saturation vapor pressure over water. Mon. Weather Rev., 88, 275-276. doi: 10.1175/1520-0493(1960)088<0275: AFFAOT $>2.0 . \mathrm{CO} ; 2$. [Link]

Bourg, D. M., 2002: Physics for Game Developers, $1^{\text {st }}$ Ed., O'Reilly \& Associates, Inc., CA, 59-60.

Bras, R., 1990: Hydrology, Addison-Wesley Pub. Co., New
York, 63-92.

CWC (Central Water Commission), 1972: Estimation of Design Flood Recommended Procedures, New Delhi, $130 \mathrm{pp}$.

Donn, W. L., 1965: Meteorology, $3^{\text {rd }}$ Ed., McGraw-HILL BOOK COMPANY, New York, 8-9.

Gagnon, R. W., D. M. Pollock, and D. M. Sparrow, 1970: Critical meteorological conditions for maximum flows, the St. François and Chaudiere river basins, Quebec. Deptartment of Transport, Meteorological Branch, Climat. Studies, 16, Toronto, Ontario, Canada.

Hansen, E. M., 1987: Probable maximum precipitation for design floods in the United States. J. Hydrol., 96, 267278. doi: 10.1016/0022-1694(87)90158-2 . [Link]

Iribarne, J. V. and W. L. Godson, 1986. Atmospheric thermodynamics, $2^{\text {nd }}$ Ed., D. Reidel Publishing Company, Dordrecht, Holland, 168-169.

Jacob, D., 2001: The role of water vapour in the atmosphere. A short overview from a climate modeller's point of view. Phys. Chem. Earth, 26, 523-527, doi: 10.1016/S1 464-1895(01)00094-1. [Link]

Jade, S. and M. S. M. Vijayan, 2008: GPS-based atmospheric precipitable water vapor estimation using meteorological parameters interpolated from NCEP global reanalysis data. J. Geophys. Res., 113, D03106, 1-12, doi: 10.1029/2007JD008758. [Link]

Jade, S., M. S. M. Vijayan, V. K. Gaur, T. P. Prabhu, and S. C. Sahu, 2005: Estimates of precipitable water vapour from GPS data over the Indian subcontinent. $J$. Atmos. Sol.-Terr. Phys., 67, 623-635, doi: 10.1016/j. jastp.2004.12.010. [Link]

Kennedy,M.R., 1982: The estimation of probable maximum precipitation in Australia past and current practice. Preprints, Proc. workshop on spillway design, Melbourne, Australia. Water Res. Conc. Ser., 6, 26-52.

Kumar, R. and L. Umanand, 2005: Estimation of global radiation using clearness index model for sizing photovoltaic system. Renew. Energy, 30, 2221-2233, doi: 10.1016/j.renene.2005.02.009. [Link]

Linsley, R. K., M. A. Kohler, and J. L. H. Paulhus, 1975: Hydrology for Engineers, $2^{\text {nd }}$ Ed., McGraw-Hill Company, New York, 16 pp.

Marvil, J., M. Ansmann, J. Childers, T. Cole, G. V. Davis, E. Hadjiyska, D. Halevi, G. Heimberg, M. Kangas, A. Levy, R. Leonardi, P. Lubin, P. Meinhold, H. O’Neill, S. Parendo, E. Quetin, N. Stebor, T. Villela, B. Williams, C. A. Wuensche, and K. Yamaguchi, 2006: An astronomical site survey at the Barcroft Facility of the White Mountain Research Station. New Astron., 11, 218-225, doi: 10.1016/j.newast.2005.06.005. [Link]

Moran, M. J., H. N. Shapiro, D. D. Boettner, and M. B. Bailey, 2011: Fundamentals of Engineering Thermodynamics, $7^{\text {th }}$ Ed., John Wiley \& Sons Inc., New Jersey, 925-926. 
Murray, F. W., 1967: Atmospheric transparency at $225 \mathrm{GHz}$ over Chajnantor, Mauna Kea, and the South Pole. J. Appl. Meteorol., 6, 203 pp.

Pan, J. and W. Teng, 1988: Determination of design flood in China. Preprints, Seizieme Congres des Grands Barrages, San Francisco. Commission Internationale de Grands Barrages, 1515-1527.

Pilgrim, D. H. and I. Cordery, 1993: Flood Runoff. In: Maidment, D. R. (Ed.), Handbook of Hydrology, New York, McGraw-Hill, 9.1-9.42.

Potter, T. D. and B. R. Colman, 2003: Handbook of Weather, Climate, and Water. John Wiley \& Sons Inc., Hoboken, New Jersey, 216-217.

Rakhecha, P. R., A. K. Kulkarni, B. N. Mandal, and R. B. Samgan, 1990: Design storm estimation of Ponnaiyar river catchment above Sathnur dam site. Hydrol. J. IAH, 13, 229-240.

Riedel, J. T., 1976: The PMP concept. Preprints, Proc. Conf. on the evaluation of dam safety, ASCE, Pacific Grounds, 415-436.

Rocken, C., T. V. Hove, J. Johnson, F. Solheim, R. Ware, M. Bevis, S. Chiswell, and S. Businger, 1995: GPS/ STROM - GPS sensing of atmospheric water vapor for meteorology. J. Atmos. Ocean. Technol., 12, 468-478, doi: 10.1175/1520-0426(1995)012<0468:GSOAWV> 2.0.CO;2. [Link]

Rogers, R. R., 1976. A Short Course in Cloud Physics. $2^{\text {nd }}$ Ed., Pergamon, New York, 15-16.

Solot, S. B., 1939: Computation of depth of precipitable wa- ter in a column of air. Mon. Weather Rev., 67, 100-103, doi: 10.1175/1520-0493(1939)67<100:CODOPW>2.0. $\mathrm{CO} ; 2$. [Link $]$

Svensson, C. and P. R. Rakhecha, 1998: Estimation of probable maximum precipitation for dams in the Hongru River catchment, China. Theor. Appl. Climatol., 59, 79-91, doi: 10.1007/s007040050014. [Link]

USNWS (United States National Weather Service), 1978: Probable maximum precipitation estimates, United States east of the $105^{\text {th }}$ meridian. Hydrometeorol. Rep., 51, Washington, DC.

USWB (United States Weather Bureau), 1949: Mean Precipitable Water in the United States. Tech. Paper, 10.

USWB (United States Weather Bureau), 1951: Table of Precipitable Water. Tech. Paper, 14.

Valeo, C., S. H. Skone, C. L. I. Ho, S. K. M. Poon, and S. M. Shrestha, 2005: Estimating snow evaporation with GPS derived precipitable water vapour. J.Hydrol., 307, 196-203, doi: 10.1016/j.jhydrol.2004.10.009. [Link]

Wallace, J. M. and P. V. Hobbs, 1977: Atmospheric Science. Academic Press Inc., Orlando, 76-77.

Wang, J., 1987: Study of design storms in China. J. Hydrol., 96, 279-291, doi: 10.1016/0022-1694(87)901594. [Link]

Wang, Y., Y. Liu, L. Liu, Z. Guo, X. Ge, and H. Xu, 2009: Retrieval of the change of precipitable water vapor with zenith tropospheric delay in the Chinese mainland. $A d v$. Space Res., 43, 82-88, doi: 10.1016/j.asr.2007.07.050. [Link] 